\title{
PbS nanopowder - synthesis, characterization and antimicrobial activity
}

\author{
M. SUGANYA, A.R. BALU* \\ PG and Research Department of Physics, AVVM Sri Pushpam College, Poondi-613 503, Tamilnadu, India
}

\begin{abstract}
Lead sulphide $(\mathrm{PbS})$ nanopowder was synthesized by a simple soft chemical route using lead nitrate and thiourea as precursor salts. The as-synthesized nanopowder was characterized by XRD, SEM, EDX, FT-IR, PL, Raman and magnetic measurements. XRD studies reveal the polycrystalline nature of the powder. The powder exhibits face-centered cubic structure with a strong (2 00 ) preferential orientation. The presence of $\mathrm{Pb}$ and $\mathrm{S}$ in the powder is confirmed by energy dispersive $\mathrm{X}$-ray analysis. The peaks observed at $1112 \mathrm{~cm}^{-1}$ and at $606 \mathrm{~cm}^{-1}$ in the FT-IR spectrum are related to heteropolar diatomic molecules of $\mathrm{PbS}$. The Raman peak shift at $173 \mathrm{~cm}^{-1}$ might have originated from the combination of longitudinal and transverse acoustic phonon modes associated with $\mathrm{PbS}$ crystal. The $\mathrm{M}-\mathrm{H}$ loop confirms the paramagnetic nature of the as-synthesized $\mathrm{PbS}$ nanopowder. The nanopowder has significant antimicrobial activity against certain bacteria and fungi strains which make it suitable as antimicrobial agent against pathogenic microorganisms.
\end{abstract}

Keywords: X-ray diffraction; photoluminescence; energy dispersive X-ray analysis; antimicrobial properties

\section{Introduction}

Nanostructured semiconducting chalcogenide materials have gained considerable attention over their bulk counterparts due to their non-linear, luminescence and useful physical and chemical properties [1]. Among the semiconducting chalcogenide nanomaterials, lead sulphide $(\mathrm{PbS})$ possesses specific optical and electronic properties due to the quantum size and dielectric confinement effects which make it more suitable in light emitting diodes, infrared detectors, optical fibers, infrared lasers, solar energy panels, etc. [2-4]. Because of tuneable nature of first excitonic transition from the visible to the infrared, $\mathrm{PbS}$ nanomaterials are well suited for infrared related applications [5]. $\mathrm{PbS}$ is an important direct band gap material with a band gap of $0.41 \mathrm{eV}$, large exciton Bohr radius of $18 \mathrm{~nm}$, high dielectric constant of 18 and high carrier mobility of $0.44 \mathrm{~cm}^{2} \cdot \mathrm{V}^{-1} \cdot \mathrm{s}^{-1}[6,7]$. Due to these properties, $\mathrm{PbS}$ possesses third order non-linear optical response 30 times better than that of GaAs and 1000 times better than CdS

*E-mail: arbalu757@gmail.com nanoparticles of similar size. Besides, $\mathrm{PbS}$ has excellent photoconductive properties [8]. In recent years, the emerging infectious diseases and the development of drug resistance against pathogenic bacteria and fungi is a matter of serious concern. Therefore, it is essential to discover new antimicrobial agents from natural and inorganic substances. The advances in the field of nanoscience and nanotechnology provided a gateway to synthesizing organic and inorganic metal particles in nanoscale regime which find applications in water treatment, medicine and therapeutics, synthetic textiles, food processing and packaging products [9]. $\mathrm{PbS}$ is a heavy metal based semiconductor which, when synthesized in nanoscale regime, might possess improved chemical, electrical, optical and magnetic properties compared to that of its bulk counterparts, which makes it an efficient antimicrobial agent also. To find the enhancement in the properties of $\mathrm{PbS}$ and its suitability as an antimicrobial agent, in this work, $\mathrm{PbS}$ nanopowder was synthesized by a simple soft chemical route and the as-synthesized powder was characterized by various techniques, such as XRD, SEM, EDX, FT-IR, PL and Raman, respectively. The antimicrobial activity study 
of the $\mathrm{PbS}$ nanopowders was performed by well diffusion method. The simple soft chemical route has been adopted here to synthesize $\mathrm{PbS}$ nanopowder as it has many advantages such as high potential, energy saving, etc.

\section{Experimental}

$\mathrm{PbS}$ nanopowder was synthesized by a simple soft chemical route. Lead nitrate, $\left(\mathrm{Pb}\left(\mathrm{NO}_{3}\right)_{2}\right.$ and thiourea $\left(\mathrm{SC}\left(\mathrm{NH}_{2}\right)_{2}\right.$, of $0.2 \mathrm{M}$ each were used as precursor salts. The salts were dissolved in deionized water $(70 \mathrm{~mL}$ in volume) and the $\mathrm{pH}$ value of this solution was found to be equal to 7.4. To this solution, $10 \mathrm{~mL}$ of liquid ammonia was added and the $\mathrm{pH}$ value was made equal to 12 . The resultant solution was stirred continuously for $6 \mathrm{~h}$ and care was taken to maintain the $\mathrm{pH}$ value of the solution constant at 12 by adding few drops of liquid ammonia. After stirring, the solution was kept undisturbed for 12 hours and the final product was washed, filtered and then calcined at $150{ }^{\circ} \mathrm{C}$ for $2 \mathrm{~h}$. The obtained product was smashed in a mortar and again it was subjected to heat treatment at $100{ }^{\circ} \mathrm{C}$ for $30 \mathrm{~min}$ to get black colored $\mathrm{PbS}$ nanopowder. The crystal structure of the powder was analyzed using X-ray diffractometer (PANalyticalPW 340/60 X'Pert PRO). The surface morphology and the elemental composition of the powder were investigated using scanning electron microscope (HITACHI S-3000H) and energy dispersive X-ray analysis. The Fourier transform infrared (FT-IR) spectra were recorded using PerkinElmer RX-1 FT-IR spectrophotometer. PL and Raman studies were performed with a Varian Cary Eclipse Fluorescence Spectrophotometer and Renishaw Invia Laser Raman microscope using a $18 \mathrm{~mW}$ $633 \mathrm{~nm} \mathrm{He}-\mathrm{Ne}$ laser. The magnetic properties of the $\mathrm{PbS}$ nanopowder were studied using vibrating sample magnetometer (Lakeshore VSM 7410). The antimicrobial activity studies were performed by agar well diffusion method against three bacterial (Bacterium staphylococcus aureus, Escherichia coli and Bacillus cereus) and two fungi (Aspergillus niger and Aspergillus terrus) strains.

\section{Results and discussion}

\subsection{Structural determination}

The XRD pattern of PbS nanopowder synthesized by soft chemical method, shown in Fig. 1, confirmed its polycrystalline nature.

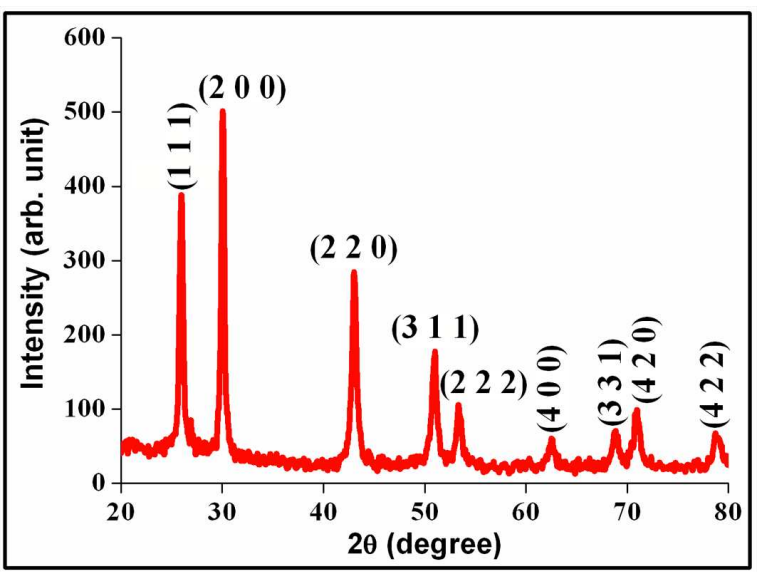

Fig. 1. XRD pattern of $\mathrm{PbS}$ nanopowder synthesized by a simple soft chemical route.

The diffraction peaks observed at $2 \theta$ values approximately equal to $25.93^{\circ}, 30.06^{\circ}, 43.02^{\circ}$, $50.99^{\circ}, 53.41^{\circ}, 62.52^{\circ}, 68.85^{\circ}$ and $70.93^{\circ}$ indexed to (1 11 1), (2 00 0), (2 20 ), (3 11 1), (2 2 2), (4 00 ), (3 3 1) and (4 20 ) planes fit well with face centered cubic structure of galena PbS (JCPDS Card No. 65-2935). It can be observed from the XRD pattern that the as-synthesized $\mathrm{PbS}$ powder exhibits a (2 000$)$ preferential orientation. The preferential orientation along the $\left(\begin{array}{lll}2 & 0 & 0\end{array}\right)$ plane observed here exactly matches with the results reported by $\mathrm{Ra}-$ jashree et al. [3] for undoped and doped PbS thin films. From the XRD pattern, the microstructural parameters such as the lattice parameter (a), crystallite size (D), strain $(\epsilon)$ and dislocation density $(\delta)$ were calculated for the $(200)$ plane using the formulae $[10,11]$ :

$$
\begin{gathered}
\frac{1}{d^{2}}=\frac{h^{2}+k^{2}+l^{2}}{a^{2}} \\
D=\frac{0.9 \lambda}{\beta \cos \theta}
\end{gathered}
$$




$$
\begin{gathered}
\varepsilon=\frac{\beta \cos \theta}{4} \\
\delta=\frac{1}{D^{2}} \text { lines } / m^{2}
\end{gathered}
$$

The lattice parameter, crystallite size, strain and dislocation density values were found to be equal to $5.946 \AA, 27.88 \mathrm{~nm}, 1.243 \times 10^{-3}$ and $1.287 \times 10^{15}$ lines $/ \mathrm{m}^{2}$, respectively.

\subsection{Surface morphology and elemental analysis}

Fig. 2a shows the SEM image of PbS nanopowder. It can be seen that the surface seems to be very smooth, composed of tightly packed grains.
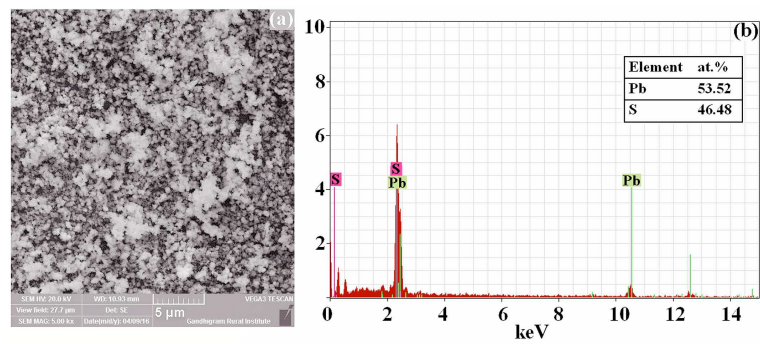

Fig. 2. (a) SEM image and (b) EDX spectrum of PbS nanopowder.

Star shaped grains corresponding to $\mathrm{PbS}$ nanopowder were also observed throughout the entire surface. The EDX spectrum (Fig. 2b) confirms the presence of $\mathrm{Pb}$ and $\mathrm{S}$ in the nanopowder. The atomic percentage composition of the elements $\mathrm{Pb}$ and $\mathrm{S}$ is given in the inset table of Fig. $2 \mathrm{~b}$. It is observed that the as-synthesized nanopowder was found to be deficient with sulfur which plays a vital role in improving its antifungi activity (Section 3.7).

\subsection{FT-IR analysis}

The Fourier-Transform Infrared (FT-IR) spectrum of $\mathrm{PbS}$ nanopowder is shown in Fig. 3.

The peak at $1946 \mathrm{~cm}^{-1}$ corresponds to $\mathrm{C}=\mathrm{O}$ stretching vibrations related to carbonyl group. The weak band observed at $1628 \mathrm{~cm}^{-1}$ is attributed to the bending vibration modes of water

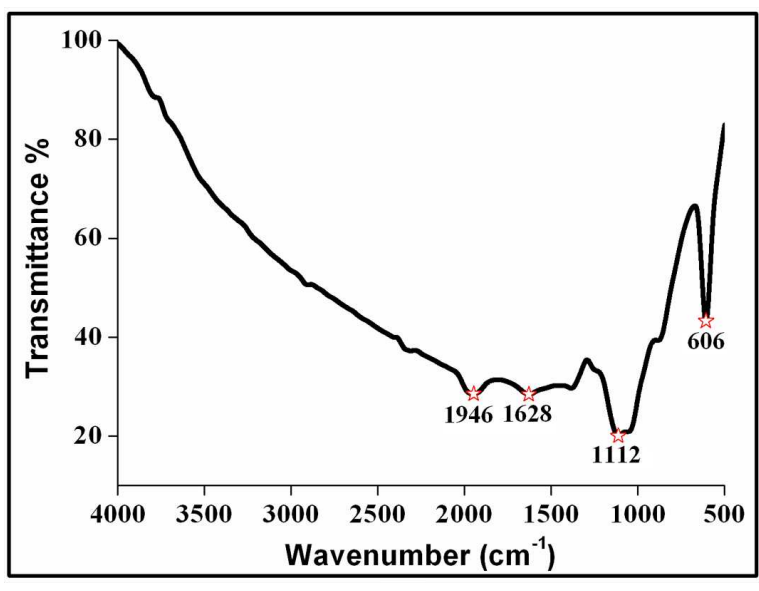

Fig. 3. FT-IR spectrum of the $\mathrm{PbS}$ nanopowder.

$(\mathrm{H}-\mathrm{O}-\mathrm{H})$ [12], which might be due to the aqueous medium used to synthesize the $\mathrm{PbS}$ nanopowder. The peaks at $1112 \mathrm{~cm}^{-1}$ and $606 \mathrm{~cm}^{-1}$ are due to heteropolar diatomic molecules of lead sulphide [13]. Besides, no strong bands associated with $\mathrm{Pb}-\mathrm{S}$ stretching and bending vibrations are observed in the FT-IR spectrum as the bond associated with $\mathrm{Pb}-\mathrm{S}$ is mainly electrovalent in nature [14]. Force constant $\mathrm{k}$ has been calculated using the equation [15]:

$$
k=4 \pi^{2}\left(\bar{\omega}^{2}\right) c^{2} \mu
$$

where $\bar{\omega}$ is the vibrational frequency and wavenumber, $\mathrm{c}$ is the velocity of light and $\mu$ is the reduced mass of the system. The force constant for $\mathrm{PbS}$ is found to be equal to $660 \mathrm{~N} \cdot \mathrm{m}^{-1}$.

\subsection{PL studies}

Fig. 4 shows the room temperature PL spectrum of $\mathrm{PbS}$ nanopowder synthesized by simple soft chemical method, excited at wavelength $\lambda=400 \mathrm{~nm}$.

Emission peaks are observed at $408 \mathrm{~nm}$, $421 \mathrm{~nm}, 487 \mathrm{~nm}$ and $520 \mathrm{~nm}$, respectively. The sharp ultraviolet peak observed at $408 \mathrm{~nm}$ ( $3.04 \mathrm{eV}$ ) infers that the synthesized PbS nanopowder has less crystal defects. This peak may be attributed to the direct transition to the valence band from the conduction band. The peak at $421 \mathrm{~nm}$ $(2.95 \mathrm{eV})$ might be due to an exciton bound to a donor level [16]. The small intensity peak 


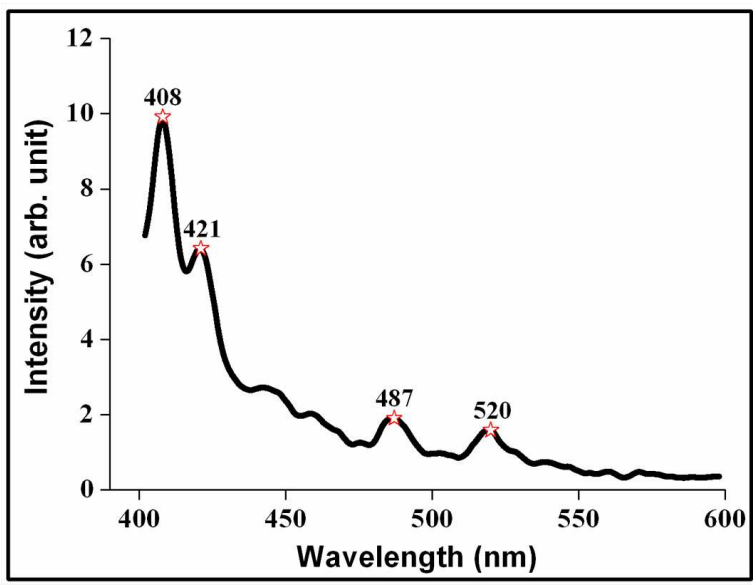

Fig. 4. PL spectrum of the $\mathrm{PbS}$ nanopowder.

observed at $487 \mathrm{~nm}(2.55 \mathrm{eV})$ corresponds to bandedge luminescence [17]. The green emission peak observed at $520 \mathrm{~nm}(2.39 \mathrm{eV})$ could be related to excitonic transitions, which might be due to the presence of electron-hole recombination via trap state or imperfection site [18].

\subsection{Raman studies}

The Raman spectra of $\mathrm{PbS}$ nanopowder are shown in Fig. 5.

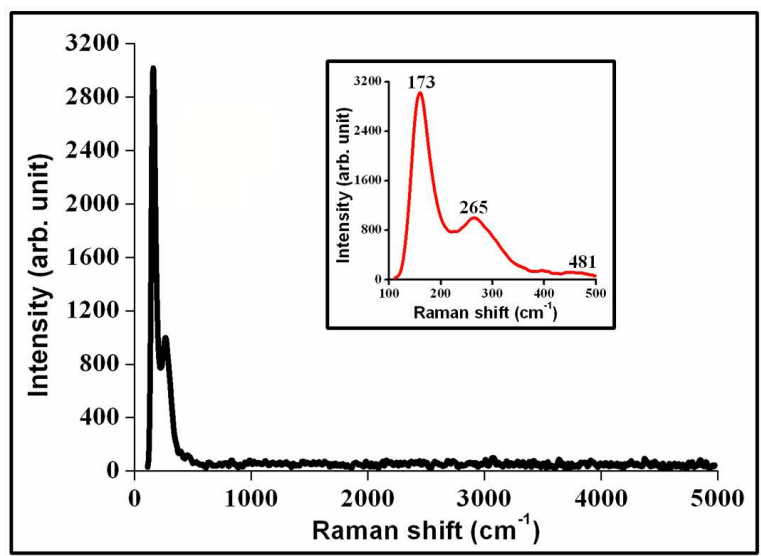

Fig. 5. Raman spectrum of the $\mathrm{PbS}$ nanopowder.

The magnified part of the spectrum in the region of $100 \mathrm{~cm}^{-1}$ to $500 \mathrm{~cm}^{-1}$ is displayed in the inset of Fig. 5. From the inset, it is observed that the spectrum shows emission peaks at $173 \mathrm{~cm}^{-1}$, $265 \mathrm{~cm}^{-1}$ and $481 \mathrm{~cm}^{-1}$. The band centered at
$173 \mathrm{~cm}^{-1}$ might have originated from the combination of longitudinal and transverse acoustic phonon modes associated with PbS crystal [19]. The peak at $265 \mathrm{~cm}^{-1}$ may be related to $\mathrm{PbO}$ formation due to photodegradation of $\mathrm{PbS}$ [20]. The peak at $481 \mathrm{~cm}^{-1}$ might be caused by formation of $\mathrm{PbO}_{2}$ as a result of laser photooxidation product of $\mathrm{PbS}$ [21]. Ovsyannikov et al. [22] observed a similar peak at $510 \mathrm{~cm}^{-1}$ assigned to the formation of $\mathrm{PbO}_{2}$. This peak came from the second overtone of fundamental longitudinal optical (LO) phonon mode 3 LO [23].

\subsection{Magnetic properties}

Vibrating sample magnetometer (Lakeshore VSM 7410) was used to investigate the magnetic properties of as-synthesized $\mathrm{PbS}$ nanopowder at room temperature. Fig. 6 shows the M-H loop of the $\mathrm{PbS}$ nanopowder.

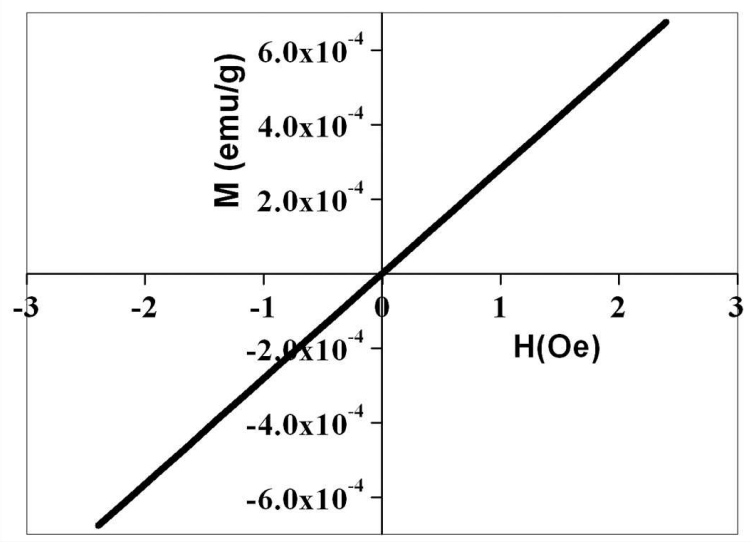

Fig. 6. M-H loop of the PbS nanopowder.

It is observed that the curve passes through zero which confirms the paramagnetic nature of the assynthesized nanopowder. No signs of ferromagnetic and anti-ferromagnetic interactions were observed in the nanopowder.

\subsection{Antimicrobial activity}

Antimicrobial activity involves relation between compounds that locally kill bacteria/fungi or slow down their growth without being in general toxic to the surrounding tissue. The most commonly used antimicrobial agents can be classified 
as either bacterial, which kill bacteria, or bacteriostatic which slow down bacterial growth. However, with their broad use and abuse, the emergence of bacterial resistance to antibacterial drugs has become a common phenomenon, which is a major problem. Because of the fact that the bacteria/fungi develop resistance against many common antimicrobial agents, infectious diseases continue to be one of the greatest health challenges worldwide. Also adequate usage of these antimicrobial agents produces adverse side effects besides resisting the pathogenic microorganisms. This prompted the development of alternative strategies to treat bacteria and fungi diseases. One such strategy is to identify new nanoscale materials which can emerge as novel antimicrobial agents. These nanoscale materials, due to their high surface area to volume ratio, have improved mechanical, chemical, electrical, optical, magnetic properties compared to that of their bulk counterparts, which makes them act as more efficient antimicrobial agents.

To assess the suitability of the $\mathrm{PbS}$ nanopowder as an antimicrobial agent, the following bacteria (Staphylococcus aureus, Escherichia coli, Bacillus cereus) and fungi (Aspergillus niger, Aspergillus terrus) strains were tested by agar well diffusion method. The stock cultures of bacteria and fungi were maintained on nutrient agar and potato dextrose slants at $4{ }^{\circ} \mathrm{C}$. Inoculums was prepared by suspending a loop full of bacteria and fungi cultures into $10 \mathrm{~mL}$ of nutrient broth inoculated at $37{ }^{\circ} \mathrm{C}\left( \pm 2{ }^{\circ} \mathrm{C}\right)$ for $24 \mathrm{~h}$ to $48 \mathrm{~h}$. Nutrient agar plates were swabbed with cultures of the above mentioned bacteria and fungi and $5 \mathrm{~mm}$ diameter wells were bored on the agar plates using sterile cork borer. $\mathrm{PbS}$ nanopowders with different concentrations $0.01 \mathrm{~g}$ and $0.02 \mathrm{~g}$ were put into the wells, and the plates were left for $1 \mathrm{~h}$ to allow pre-incubation diffusion in order to minimize the effects of variation in time between the application of different solutions. The plates were incubated in an upright position maintained at $37{ }^{\circ} \mathrm{C}$ for 24 hours.

Fig. 7 shows the antimicrobial activity of the $\mathrm{PbS}$ nanopowders against the bacteria and fungi strains, which is confirmed by the formation of zones around the powders.

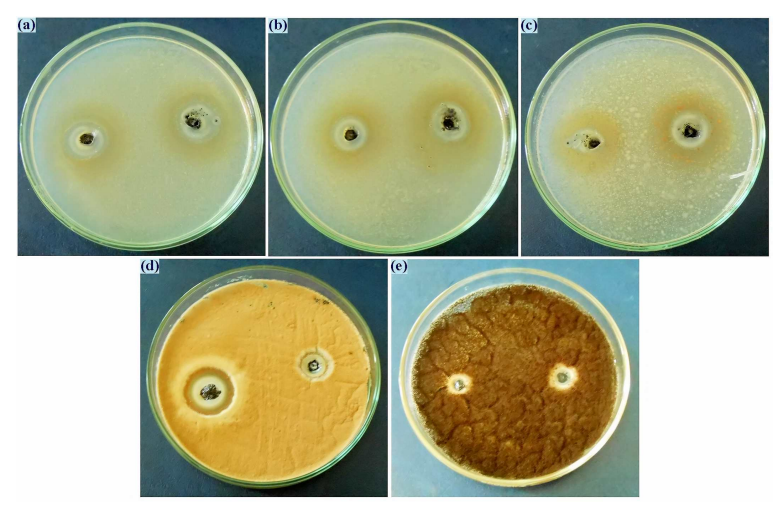

Fig. 7. Antimicrobical activity of $\mathrm{PbS}$ nanopowders against bacteria (a) Staphylococcus aureus, (b) Escherichia coli, (c) Bacillus cereus and fungi (d) Aspergillus niger, (e) Aspergillus terrus strains.

The antimicrobial activity of the $\mathrm{PbS}$ nanopowders was estimated by measuring the diameters of zone of inhibition in millimetre scale. The samples were tested in triplicates and the average values of the diameters of zone of inhibition obtained are given in Table 1.

Significant antimicrobial activity of the nanopowders was observed against gram-negative bacteria $(E$. coli), gram-positive bacteria $(B$. cereus) and against fungi (A. terreus). The nanopowders show moderate antimicrobial activity against gram-positive bacteria ( $S$. aureus) and fungi (A. niger). The significant antibacterial activity possessed by $\mathrm{PbS}$ nanopowders against gram-negative bacteria, when compared to that of the gram-positive bacteria, might be due to the cell wall nature of the bacteria. The gram-negative bacteria possess slender layer of membrane, whereas the gram-positive bacteria possess deep layer of membrane, consisting of linear polysaccharide chains. The antibacterial activity of $\mathrm{PbS}$ nanopowders is ascribed to a combination of factors that include generation of reactive oxygen species (ROS) and efflux mechanisms leading to the release of constituent ions [24]. It has been reported earlier that $\mathrm{Pb}^{2+}$ ions cause toxicity by interacting with nucleic acids by binding to essential respiratory proteins through oxidative damage caused by production of reactive oxygen 
Table 1. Zone of inhibition of $\mathrm{PbS}$ nanopowders against certain bacteria and fungi strains.

\begin{tabular}{cccc}
\hline & & \multicolumn{2}{c}{ Zone of inhibition [mm] } \\
& Microorganism & PbS powder concentration \\
& & $0.01 \mathrm{~g}$ & $0.02 \mathrm{~g}$ \\
\hline \hline \multirow{3}{*}{ Bacteria } & Escherichia coli (E. coli) & 12 & 14 \\
& Staphylococcus aureus (S. aureus) & 5 & 10 \\
& Bacillus cereus (B. cereus) & 7 & 11 \\
\hline \multirow{2}{*}{ Fungi } & Aspergillus terrus (A. Terreus) & 6 & 19 \\
& Aspergillus niger (A. niger) & 4 & 6 \\
\hline
\end{tabular}

species [25]. $\mathrm{Pb}^{2+}$ ions enter bacterial cells via transport systems and the cells respond to it by metal inducible resistance mechanisms.

The presence of intrinsic defects in $\mathrm{PbS}$ nanopowder produces electron-hole pairs, as evidenced by the PL and Raman spectra. These holes react with water, producing $\mathrm{H}^{+}$and $\mathrm{OH}^{-}$ions and the electrons convert the dissolved oxygen molecules to superoxide radical anions. So obtained superoxide radical anions react with $\mathrm{H}^{+}$producing $\mathrm{HO}_{2}$ radicals which then get converted to hydrogen peroxide anions $\left(\mathrm{HO}_{2}^{-}\right)$. Hydrogen peroxide is then obtained by the reaction of these anions with hydrogen ions, and the obtained hydrogen peroxide penetrates the fungi cell membrane and disrupts it due to oxidative stress [26]. In $\mathrm{PbS}$ nanopowder, the presence of $\mathrm{S}$ vacancies is the most obvious source of band transitions leading to the generation of $\mathrm{H}_{2} \mathrm{O}_{2}$. The presence of $\mathrm{S}$ vacancies has been well acknowledged by the EDX analysis (Section 3.2). The observations made here confirm that the $\mathrm{PbS}$ nanopowder emerges as a potential antibacterial and antifungal agent thereby resisting the growth of pathogenic bacteria which cause respiratory illness, pneumonia, urinary infections, food borne illness and fungi related infections.

\section{Conclusions}

$\mathrm{PbS}$ nanopowder was successfully synthesized by a simple soft chemical route method. XRD studies confirmed that the $\mathrm{PbS}$ nanopowder exhibited face-centered cubic structure with a preferential orientation along the $\left(\begin{array}{lll}2 & 0 & 0\end{array}\right)$ plane. The lattice parameter, crystallite size, strain and dislocation density values were found to be equal to $5.946 \AA$, $27.88 \mathrm{~nm}, 1.243 \times 10^{-3}$ and $1.287 \times 10^{15}$ lines $/ \mathrm{m}^{2}$, respectively. The FT-IR spectra confirmed the presence of stretching vibrations of $\mathrm{Pb}-\mathrm{S}$ at $606 \mathrm{~cm}^{-1}$. The $\mathrm{PbS}$ nanopowder was found to be paramagnetic in nature. The antimicrobical activities of $\mathrm{PbS}$ nanopowders confirmed that they can be used as an antimicrobial agent resisting the growth of pathogenic bacteria and fungi strains which make them suitable for nanodrug design as well as medicinal and pharmaceutical applications.

\section{Acknowledgements}

The authors thank the Head, Department of Chemistry, Gandigram Rural University, Dindugal, for the SEM and EDX measurements.

\section{References}

[1] Bagade C.S., Ghanwat V.B., Knot K.V., BhosALE P.N., Mater. Lett., 164 (2016), 52.

[2] Voit J., Rep. Prog. Phys., 58 (1994), 977.

[3] Rajashree C., Balu A.R., Nagarethinam V.S., Surf. Eng., 31 (2015), 316.

[4] Peterson J.J., Krauss T.D., Nano Lett., 6 (2006), 510.

[5] Mcdonald S.A., Konstantatos G., Zhang S., Cyr P.W., Klem J.D.E., LeVina L., SARgent E.H., Nat. Mater., 4 (2005), 138.

[6] InUk K., Frank W.W., J. Opt. Soc. Am., 14 (1997), 1632.

[7] Scanlon W.W., Phys. Rev., 109 (1958), 47.

[8] Wang Y., Accounts Chem. Res., 24 (1991), 133.

[9] Gajuar P., Pettee B., Britt D.W., Huang W., Johsnon W.P., ANDERSON J., J. Biol. Eng., 3 (2009), 9.

[10] Usharani K., Balu A.R., Acta Metall. Sin., 28 (2015), 64.

[11] Ravishankar S., Balu A.R., Anbarasi M., NAGARETHINAM V.S., Optik, 126 (2015), 2550. 
[12] Vaezi M.R., SadrnezhaAd S.K., Mater. Design, 28 (2007), 515.

[13] Borhade A.V., Uphade B.K., Chalcogenide Lett., 9 (2012), 299.

[14] Pawar S.B., Shaikh J.S., Devan R.S., Ma Y.R., Haranath D., Bhosale P.N., Patil P.S., Appl. Surf. Sci., 258 (2011), 1869.

[15] Banwell C.N., MCCASH E.M., Fundamentals of molecular spectroscopy, Tata McGraw Hill, New Delhi, 2010.

[16] Selvan G., Abubaker M.P., Usharani K., Balu A.R., Surf. Eng., 32 (2015), 212.

[17] Murali G., Reddy D.A., Sambasaivam S., GiribabU G., Vijayalakshmi R.P., Venugopal R., REDDY B.K., Mater. Lett., 93 (2013), 149.

[18] Chaure S., Chaure N.B., Pandey R.K., Physica E, 28 (2005), 436.

[19] Smith G.D., Firth S., Clark R.J.H., CARDONA M., J. Appl. Phys., 92 (2002), 4375.
[20] Shapter J.G., Brooker M.H., Skinner W.M., Int. J. Miner. Process., 60 (2000), 199.

[21] Burgio L., Clark R.J.H., Firth S., Analyst, 126 (2001), 222.

[22] Ovsyannikov S.V., ShChennikov V.V., Cantarero A., Cross A., Titov A.N., Mat. Sci. Eng. A-Struct., 462 (2007), 422.

[23] Huang Q.L., Chen H., Wu C.L., Zhang Y.C., Mater. Lett., 64 (2010), 1891.

[24] Perkas N., Lipovsky A., Amirian G., Nitzan Y., GedAnKen A., J. Mater. Chem., 8 (2013), 5309.

[25] Stohs S.J., Bagehi D., Free Radical Bio. Med., 18 (1995), 321.

[26] Applerot G., Lipovsky A., Dror R., Perkas N., Nitzan Y., Lubart R., Gedanken A., Adv. Funct. Mater., 19 (2009), 842.

Received 2016-07-03 Accepted 2017-03-19 